\title{
Historizar el territorio y espacializar la historia a través de la cartografía hidráulica en Mendoza, Argentina (s. XVI-XVIII)
}

\author{
Jorge Ricardo Ponte \\ Instituto de Ciencias Humanas, Sociales y Ambientales \\ Consejo Nacional de Investigaciones Científicas y Técnicas (Argentina) \\ jorgericardoponte@gmail.com
}

\begin{abstract}
Resumen. En América, en general, y en el territorio sudamericano que conformó el Imperio Incaico, en particular, existió una cultura hidráulica, consistente en refinadas técnicas de represas, canales y acequias que condicionaron la implantación del asentamiento urbano español. En el período colonial existieron numerosos litigios por problemas del uso del agua (potable y de riego) que portaban las acequias. Estos conflictos entre vecinos, entre ellos e instituciones religiosas, entre vecinos y molineros, etc., fueron, muchas veces, acompañados de planos explicativos que intentaban argumentar, gráficamente, dichas disputas. Por otro lado, existen en el territorio cuestiones topográficas, tales como ríos secos, cañadones, barrancos, cambios abruptos de pendientes, cursos de agua, ríos, arroyos, etc. que, aunque vienen desde tiempos inmemoriales, no fueron registrados en los primeros planos coloniales y sí, en cambio, en los del siglo XIX. Por ello, nuestro objetivo es mostrar las posibilidades que se abren en la investigación histórica, mediante la utilización de la cartografía hidráulica histórica re visitada con la tecnología digital. Finalmente, se hace necesario y evidente tener como premisa la necesidad de "incorporar espacio a la historia e historia al territorio". Solo espacializando la historia, o el relato histórico, e historizando el espacio social y cultural podremos comprender y modificar la tensión que anida entre la historia y el territorio.
\end{abstract}

Palabras clave. Planos hidráulicos, territorio, historia, ciudad, digitalización.

\begin{abstract}
Historicizing territory and spatializing history through hydraulic mapping en Mendoza, Argentina (XVI-XVIII). In America, in general and in the South American territory that formed the Inca empire, in particular, there was a hydraulic culture, consisting of refined techniques for dams, canals and ditches that conditioned the implementation of the Spanish urban settlement. In the colonial period there were numerous disputes over issues of water use (drinkable and for irrigation). These conflicts between neighbors and religious institutions, and among neighbors and millers, were often accompanied by explanatory drawings that intended to argue such disputes, graphically. On the other hand, there are questions of topographical territory, such as dry rivers, canyons, ravines, abrupt changes in slope, streams, rivers, creeks. Issues that, although having existed for centuries, were not recorded in the early colonial maps but were however, in the nineteenth century. Therefore, our objective is to show the possibilities that open up historical research when using hydraulic mapping to re visit history with digital technology. Finally, it is necessary and obvious to be clear on the need to "incorporate space to history and history to territory." Only by spatializing history or the historical account, and historicizing the social and cultural spaces can we understand and modify the tension that lies between history and territory.
\end{abstract}

Keywords. Hydraulic maps, landscape, history, cities, digitalization.

\section{Introducción}

El actual Área Metropolitana de Mendoza se encuentra dentro del conjunto de tierras áridas del piedemonte de la cordillera de los Andes. Fue fundada a mediados del siglo XVI por la corriente colonizadora de Chile y como Corregimiento de Cuyo perteneció a la Capitania General de Chile hasta 1776, fecha en que pasó a integrar el recién creado Virreinato del Río de la Plata origen de la actual Argentina.

Antes de la llegada del conquistador español a las tierras de Cuyo ${ }^{1}$ existía, en lo que hoy constituye el actual Área Metropolitana de Mendoza, una cultura hídrica en pleno

1 Cuyo o Cuyum palabra huarpe que significaba "tierra de las arenas" y que denota la característica árida del suelo (Maza, 1990). 
funcionamiento. El soporte geográfico donde se asienta este territorio comprende un piedemonte, limitado al oeste por la pre-cordillera y al este por una planicie o llanura:

'La ciudad se encuentra ubicada en la subunidad geomorfológica denominada playa. Hacia el oeste de la misma se ubica el piedemonte y la montaña. La unidad montañosa es la Precordillera (sierra de Uspallata) macizo antiguo con gran abrupto de fallas. De él descienden las corrientes de agua que drenan una extensa penillanura. El piedemonte se divide en dos niveles de glacis: superior e inferior. Del primero sólo quedan restos en tiras perpendiculares a la montaña. El segundo también llamado principal por su extensión, domina el paisaje. Desde el contacto con la montaña a $1500 \mathrm{~m}$. sobre el nivel del mar, desciende suavemente hasta perderse debajo de la playa a $800 \mathrm{~m}$. de altura. (...) Está suavemente inclinada al noreste y se extiende entre las cotas de 800 y $700 \mathrm{~m}$. sobre el nivel del mar" (Cortellezi et al., 2013).

En este soporte orográfico próximo a la planicie se origina una serie irregular de bajadas aluvionales por donde discurren las aguas durante las intempestivas tormentas estivales. Fuera de estos fenómenos meteorológicos puntuales, todo el sistema se presentaba como una red de ríos secos o zanjones, con fuerte pendiente oeste-este que se diluían en la planicie luego de horadar, profundamente, su paso por el glacis.

El sistema hídrico tenía su origen en el, por entonces, llamado Río de Cuyo (actual río Mendoza) de origen cordillerano y que se nutre de las aguas de deshielos de los glaciares de la cordillera de los Andes, la "cordillera nevada" como se la llamaba en las primeras crónicas coloniales.

Este sistema hídrico fruto de la racionalidad del aprovechamiento del agua, no se sabe cuándo se habría sistematizado, ya que es absolutamente artificial, es decir: cultural. Como tanto las culturas "huarpe" como la "Inca" fueron culturas ágrafas y, por lo tanto, no existen registros sobre su origen. Puede presumirse, y de hecho se hace, que habrían sido los propios Incas, notables hidráulicos ellos, como lo atestiguan las obras supérstites en el Cusco y alrededores, quienes, a su llegada a estas tierras de Cuyo en el año 1480 (c.) habrían ayudado a los naturales a organizar el sistema de riego y provisión de agua potable.

Es decir, los españoles no encontraron en el Valle de Huentata solamente aborígenes disponibles para ser usados como mano de obra servil, sino toda una cultura hídrica que los entornaba y que no sólo les permitía el sustento y la supervivencia sino que también producía excedentes agrícolas que eran elevados al Inca como tributos por parte de los naturales.

El levantamiento de planos, o mapas, en la América colonial austral estuvo restringido, tanto fuera desde el punto de vista material como simbólico. En lo material por la escases de papel que existieron en estos reinos y la necesidad de aprovechar al máximo los pliegos disponibles.

Desde el punto de vista de lo simbólico en los tiempos que gobernaban los Austrias (15161714) se confeccionaron los planos fundacionales (dos) y luego se produjo un gran silencio cartográfico. Deberemos esperar hasta 1754, cuando en la metrópoli reinaba Felipe V de Borbón, para que en Mendoza aparezca, azarosamente, el primer plano real de la ciudad fundada hacía ya 193 años.

El primer plano territorial levantado, un plano idealizado, fue confeccionado por el fundador en 1561 para mostrar y asentar y registro dela asignación de chacras $^{2}$ más allá del

2 Chacra. (Del quechua ant. chacra, mod. chajra). 1. f. Am. Mer. Alquería o granja. RAE 
ejido de la recién fundada ciudad. En rigor exacto, el asentamiento buarpe que ya existía en el denominado por los aborígenes como Valle de Huentata (que significaba valle de los guanacos $^{3}$ ), no era ni siquiera una aldea. Se presume que los huarpes se localizaban, cada cacique, su familia y descendientes, a lo largo de cada acequia de las muchas existentes. Los nombres huarpes de estas acequias los desconocemos al tiempo de la fundación, pero irán apareciendo y blanqueándose a medida que comenzara la vida de la ciudad colonial.

Ante la posibilidad que su fundación fuera cuestionada (Ponce, 2008) por implantar ciudad española en el ámbito de "pueblo de indios", algo que prohibirán las Leyes de Indias en 1573. El fundador, Pedro del Castillo, evita referirse a la culturalización que presupone un sistema de acequias, cultivos, caminos y asentamientos habitacionales en el largo trayecto de $20 \mathrm{~km}$ que median entre el entonces Río de Cuyo y la fundación española.

Por otro lado, podemos imaginar la sorpresa que significó para este funcionario español proveniente, a su vez, del valle del Río Oja, recorrer más de10.000 km para encontrarse aquí, con otro valle irrigado con canales y acequias como en su Rioja natal ${ }^{4}$. Por eso, seguramente, llamó a su ciudad recién fundada: "nuevo valle de Rioja".

Cuando el fundador de la ciudad, don Pedro del Castillo decidió plantar "Mendoza, nuevo valle de Rioja" el 2 de marzo de 1561 estableció un casco fundacional mínimo de cinco por cinco manzanas (aprox. 25 has). Entre el casco fundacional, que definió mediante un primer plano idealizado y el inicio de las chácaras o quintas (que definió mediante otro plano específico) se encontraba el llamado ejido de la ciudad ${ }^{5}$. Una superficie común que, en el caso de Mendoza fue de 491,7 has superficie de uso común que, por entonces, entornaba al casco urbano y hacía de fuelle entre el casco fundacional y la zona rural propiamente dicha. Según señala Page para la ciudad de Córdoba (Argentina).

"El ejido era proporcional al tamaño de la ciudad y su uso era en teoría disponible únicamente para los vecinos y, aunque las leyes lo restringían, los funcionarios del Cabildo obtuvieron concesiones. De hecho el puñado de hombres llegados con el fundador debieron hacerse cargo de la administración de la incipiente ciudad, por lo que cargos públicos había para todos." (Page, 2004).

El $2^{\circ}$ plano de 1561 (también idealizado) estableciendo las chácaras y quintas para los

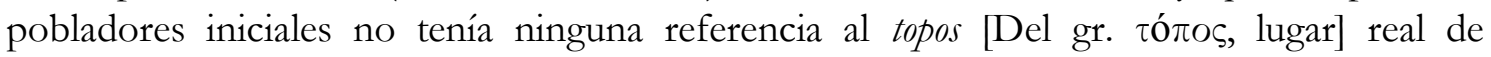
Mendoza (entiéndase éste por zanjones, ríos secos, canales y acequias, que sabemos que preexistían a la llegada de los conquistadores), salvo indicar los cuatro puntos cardinales. Este plano de repartimientos ha sido tomado poco en serio, y tenido más bien como una declaración de intenciones de ocupación del territorio más que un plano real que reflejara pretensiones reales de posesión y dominio. Pero, en un ejercicio de traspaso sobre topos de la ciudad real vemos que tenía mucha lógica (ver Fig. 4).

En realidad, ha costado imaginar que este $2^{\circ}$ plano del Capitán Pedro del Castillo fuera el comienzo de todo el desarrollo parcelario de la ciudad y alrededores en los siglos venideros.

$3 \mathrm{El}$ guanaco es un camélido que vivía en la toda zona cordillerana sudamericana que bajaba al llano en búsqueda de pasturas tiernas.

4 La Rioja en España, su lugar de origen, había estado bajo el poder musulmán entre el año 711 y el 1031. De allí el conocimiento de las acequias, palabra de origen árabe que significa: (Del ár. hisp. assáqya, y este del ár. clás. säqiyah 'irrigadora'). 1. f. Zanja o canal por donde se conducen las aguas para regary para otros fines. RAE.

5 Ejido: (Del lat. *exitus, por exitus, salida).1. m. Campo común de un pueblo, lindante con él, que no se labra, y donde suelen reunirse los ganados o establecerse las eras [era2. (Del lat. arĕa).1. f. Espacio de tierra limpia y firme, algunas veces empedrado, donde se trillan las mieses. 2. f. Cuadro pequeño de tierra destinado al cultivo de flores u hortalizas. RAE 


\section{E1 topos ausente en el Acta fundacional de Mendoza de 1561}

Donde el Acta fundacional dice: "me pareció conbenia en este dicho asiento y valle alçar rollo" debiera haber dicho: ... Visto que este asiento y valle de Guantata se encuentra surcado por una red de acequias y canales preestablecidos desde tiempos antiguos por los aborígenes Huarpes y, considerando que dada la sequedad del clima de esta región no existen otras alternativas de instalar un asentamiento humano lejos de esos canales y acequias y que, trazados o no por estos aborígenes Huarpes, éstos se sirven de ellos como proveedores de agua potable y de riego para sus chacras y cultivos; y siendo nuestra intención establecer aquí las futuras chacras y huertas, se hace necesario parlamentar con los caciques locales para ver qué sitios tienen ellos libres y disponibles para que nosotros podamos instalar un asentamiento humano con forma de cuadrícula y una zona anexa de chacras y huertas para sustento y abastecimiento de la ciudad.

El topos local, además del sistema de regadío artificial, se complementaba con una serie de zanjones y ríos secos, con sentido sudoeste-nordeste, formados desde tiempo inmemorial, que constituían bajadas aluvionales desde la precordillera mendocina. Estos zanjones o ríos secos surcaban la suave planicie en declive sobre la que discurría el Goazap Mayu ${ }^{6}$ y su red hídrica secundaria. Los había de distinta magnitud y profundidad. Desde suaves hondonadas hasta verdaderos cauces de ríos secos.

Tal fue la fuerza del "topos” geográfico donde se implantó la ciudad de Mendoza que todas las decisiones parcelarias dependerán de él. Así, si debía establecerse un límite de una parcela rural o urbana ésta se alargaba o acortaba de manera de coincidir con alguno de estos zanjones, que no sólo dividían propiedades sino que eran, también, mojones de referencias en el territorio. Así, las propiedades se referenciaban por su cercanía o lejanía a los zanjones próximos o importantes, ejemplo: dos o tres zanjones más hacia el sur o hacia el norte.

Estos zanjones secundarios, a su vez, desaguaban en zanjones mayores o principales, los que solían tener nombres propios, a saber: Zanjón de los Ciruelos, de Guiñazú, de Frías, de Mayorga, etc.

\section{La voz ausente -la de los aborígenes huarpes- en el relato fundacional}

Lo que no dijo el Capitán del Castillo en 1561 en su Acta Fundacional, lo dijeron años después (el 01/09/1574 ) los caciques comarcanos convocados a tal efecto por el Cabildo de la Ciudad. Ellos fueron, a saber: $\mathrm{D}^{\mathrm{n}}$ Felipe Esteme , $\mathrm{D}^{\mathrm{n}}$ Hernando Goaymaye, $\mathrm{D}^{\mathrm{n}}$ Diego Añato y el cacique Allalloa y otros caciques principales. Los cabildantes entonces les solicitaron que declarasen y dijesen que tierras había vacías hacia 1574 en esta ciudad, por un lado y, por el otro, que se señalase los terrenos que se había dado, en 1561 al Capitán Pedro del Castillo, el fundador de la Ciudad de Mendoza.

$6 \mathrm{El}$ actualmente conocido como Canal Zanjón en su porción comprendida entre la Toma en el Río hasta la actual zona del Pilar donde doblaba bruscamente en ángulo recto [desagüe antiguo] para dar origen al actual canal Confín Desagüe] fue conocido en tiempos prehispánicos, es decir, antes de la llegada del fundador Pedro del Castillo como Goazap-Mayu nombre que en lengua quechua significaría "río del Cacique Goazap”. 
$\mathrm{D}^{\mathrm{n}}$ Felipe Esteme dijo que él, como "Señor de este valle y tierras" había dado y señalado al Capitán Pedro del Castillo al tiempo que fundó y pobló esta ciudad, las tierras que corrían por las acequias que salían del río de esta ciudad [actual río Mendoza]. Los demás caciques presentes dijeron que era verdad todo lo que había dicho $\mathrm{D}^{\mathrm{n}}$ Felipe acerca de los terrenos. Vista, por parte de los cabildantes la razón expuesta por los caciques, se acordó que allí se señalasen y amojonasen los terrenos que se habían dado, oportunamente al Capitán Pedro del Castillo.

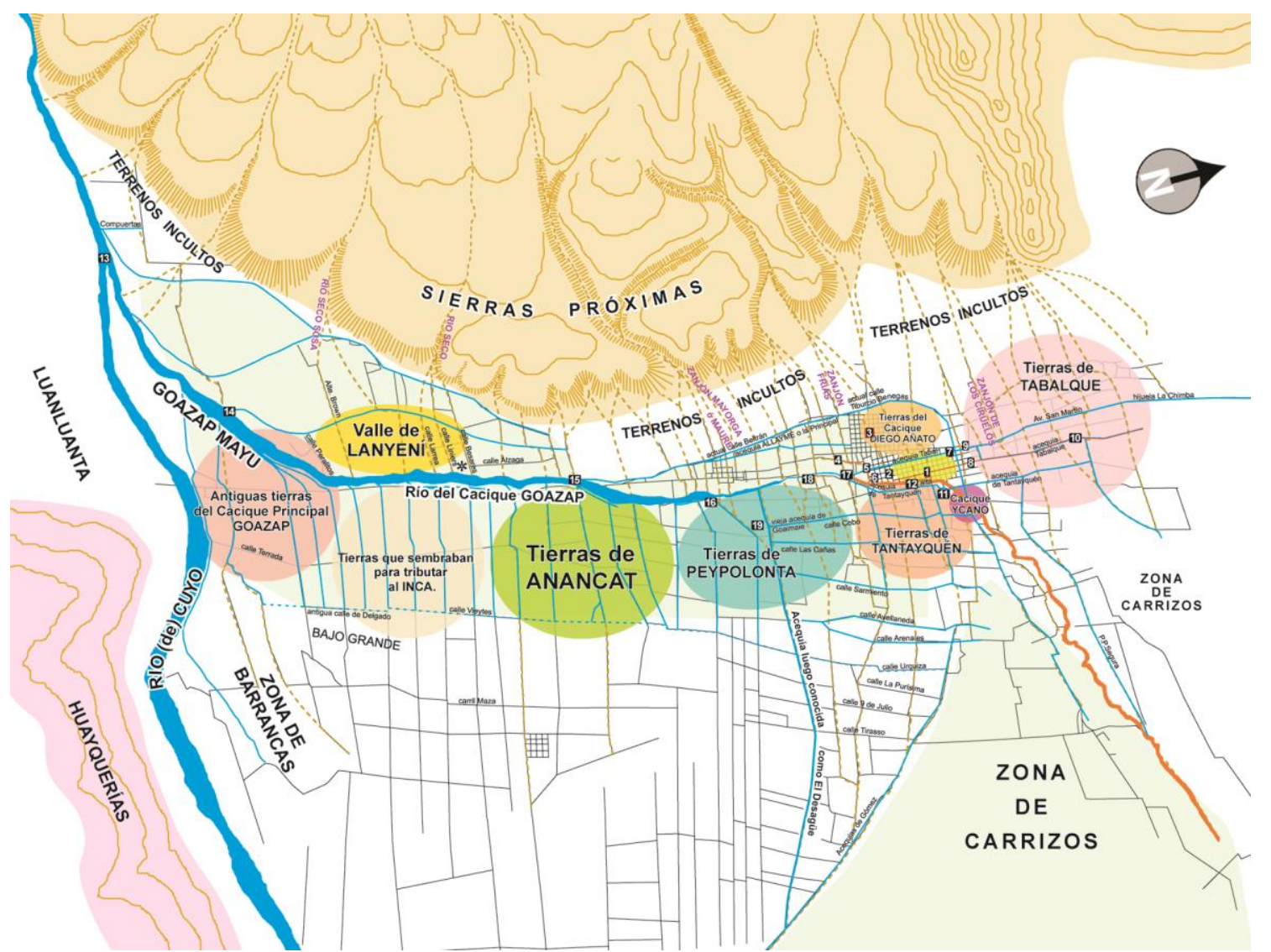

Fig. 1. Sistema de cauces aluvionales y acequias y asentamiento huarpe antes de 1561.

$\mathrm{D}^{\mathrm{n}}$ Felipe Esteme confirmó que cuando el Capitán del Castillo vino con los españoles a poblar esta ciudad, estaba Goaymaye y sus indios poblando estas tierras llamadas Peypolontay les dijo que se quedasen en ellas porque él se holgaba en la zona asignada. Después de la llegada del Capitán del Castillo y los que con él venían, Goaymaye y sus indios, se establecieron un poco más abajo, en unas tierras llamadas Tantayquen [actual distrito de San José en Guaymallén] y que eran propiedad original del cacique $\mathrm{D}^{\mathrm{n}}$ Felipe. Goaymaye dijo que su madre, llamada Estepe, dio al cacique Coyo "una oveja de la tierra" para que les dejase a ella y a sus indios, sembrar en esas tierras de Tantayquen y que por ello, él y sus indios, en ese tiempo se habían pasado y venido a éstas.

7 Por "oveja de la tierra" debe reconocerse a la llama la más grande de los camélidos, mide de 150 a $190 \mathrm{~cm}$. de altura con un peso máximo de unos $140 \mathrm{Kg}$. (...) Es domesticable y usada como animal de carga y para carne. (...) puede portar unos $40 \mathrm{Kg}$. en viajes largos, y hasta unos $60 \mathrm{Kg}$. (...) Su lana, la más gruesa de los camélidos, da unos $4 \mathrm{Kg}$. con esquila cada 2 años. http://www.clinamen.cl/Nortegrande/Camelidos/

Llama.htm 
Los caciques $\mathrm{D}^{\mathrm{n}}$ Felipe Esteme, Goaymaye, Allalloa, el principal Ulitian, Acmayen y demás caciques y principales que estuvieron presentes, excepto $\mathrm{D}^{\mathrm{n}}$ Diego Añato aseveraron que todo era así como se dijo traducción mediante, hecha por el Señor Justicia Núñez de Cepeda regidor de la ciudad, quien hablaba y entendía bien la lengua de los naturales de esta tierra. Se amojonaron y señalaron los predios que estaban vacíos y firmaron el acta que ha pasado a la historia como el Acta de los Caciques Comarcanos de 1574.

Los caciques hablan en términos y saberes de su tiempo, sin pensar que tendrían que ayudarnos a identificar los accidentes geográficos o los cursos de agua, de manera de facilitarnos la tarea a los historiadores del presente. Obviamente, los caciques a la hora de situar las tierras entregadas a Castillo, no lo hacen en los términos abstractos de los europeos: norte, sur, este y oeste, sino que usan como indicadores: unas construcciones de barro, los paredones; los cursos de agua -las acequias- y los nombres de los caciques vecinos. Así, ellos señalan 6 referencias ${ }^{8}$, a saber:

1) Los paredones [que conoceremos luego como los paredones del Inca] ubicados hacia el Este del actual canal-zanjón cacique Guaymallén.

2) La acequia que naciendo en los paredones va a caer en el carrizal [y que describe un gran arco que naciendo desde el Este, enfila al sesgo hacia el oeste para caer, finalmente, hacia el Este].

3) La acequia alta de Tantayquen [ubicada hacia el Este del actual canal-zanjón cacique Guaymallén].

4) Las tierras del cacique Allalloa [ubicadas al inicio de la acequia Tabal, que iba sesgada desde los paredones hacia el norte, o sea, desde la Acequia Grande de la Ciudad [actual Canal Zanjón] y que luego discurría en dirección al norte, para "caer", finalmente, hacia el Este] caer en el carrizal.

5) Las tierras del cacique Añato que era quien babia "ofrecido" sus tierras "vacas" [arcaísmo por vacías] en el corazón de la hoy conocida como Área Fundacional de Mendoza.

6) Las tierras donde estaba asentado el cacique Goaymaye [ubicadas hacia el este del actual canalzanjón cacique Guaymallén].

Si nos atenemos a lo que dice el Acta de los Caciques Comarcanos de 1574, los españoles no tenían ante sí un espacio vacío, ni de gente ni de siembras, donde fundar ciudad, sino, todo lo contrario, un espacio ocupado, histórica y culturalmente, por los Huarpes que eran los naturales de esta zona. Ellos, según dicha Acta habrían "cedido" las tierras vacas(vacías) posibles.

Los españoles no se alertaron del mal emplazamiento que les habían otorgado los indios, sino cuando ya tenían todo armado, los solares repartidos, los primeros ranchos construidos, y las primeras avenidas de agua o aluviones vividos. Los terrenos de San José en el actual Dpto de Guaymallén fue, en los primeros tiempos de la ciudad, una zona de indios y luego los propios arrabales de Mendoza.

8 Resulta curioso que los caciques comarcanos dan mucha más precisión respecto del sitio donde se fundó la ciudad que el propio fundador, el español Pedro del Castillo, quien señala vagamente en el Acta Fundacional que la fundación se hace en este asiento y valle donde están los indios. 


\section{$4 \mathrm{El}$ plano de "Repartimiento de tierras a los primeros pobladores de la ciudad de}

Mendoza" traspasado sobre un plano contemporáneo

El original del plano de "Repartimiento de tierras a los primero pobladores de la ciudad de Mendoza" hecho por el Capitán don Pedro de Castillo se encuentra en el Archivo General de Indias, MP-BUENOS_AIRES, 222. El estado de legibilidad del documento es bastante deficiente. De todas maneras podemos advertir las siguientes intenciones del fundador, a saber:

a) El casco urbano de cinco por cinco manzanas con una plaza central se encuentra en el centro mismo del trazado.

b) Un ejido rodea al casco urbano y posee también como éste, en el dibujo, las proporciones de un cuadrado más grande donde está inserto el casco urbano. Los límites de éste a los bordes del ejido son equidistantes.

c) La distribución de chacras en el territorio no es pareja en todas las orientaciones sino que, hacia la porción sur del ejido, se proponen más parcelas (tres filas) mientras que hacia las otras orientaciones se proponen una sola fila para cada una.

d) Estas parcelas rurales, de forma rectangular todas, todastienen el lado menor del rectángulo, mirando hacia el ejido. La mayoría de las propiedades son de dos cuadras por el lado menor y de tres cuadras por el lado mayor, o sea, de fondo. Hay también parcelas de tres cuadras de largo por tres cuadras de fondo.

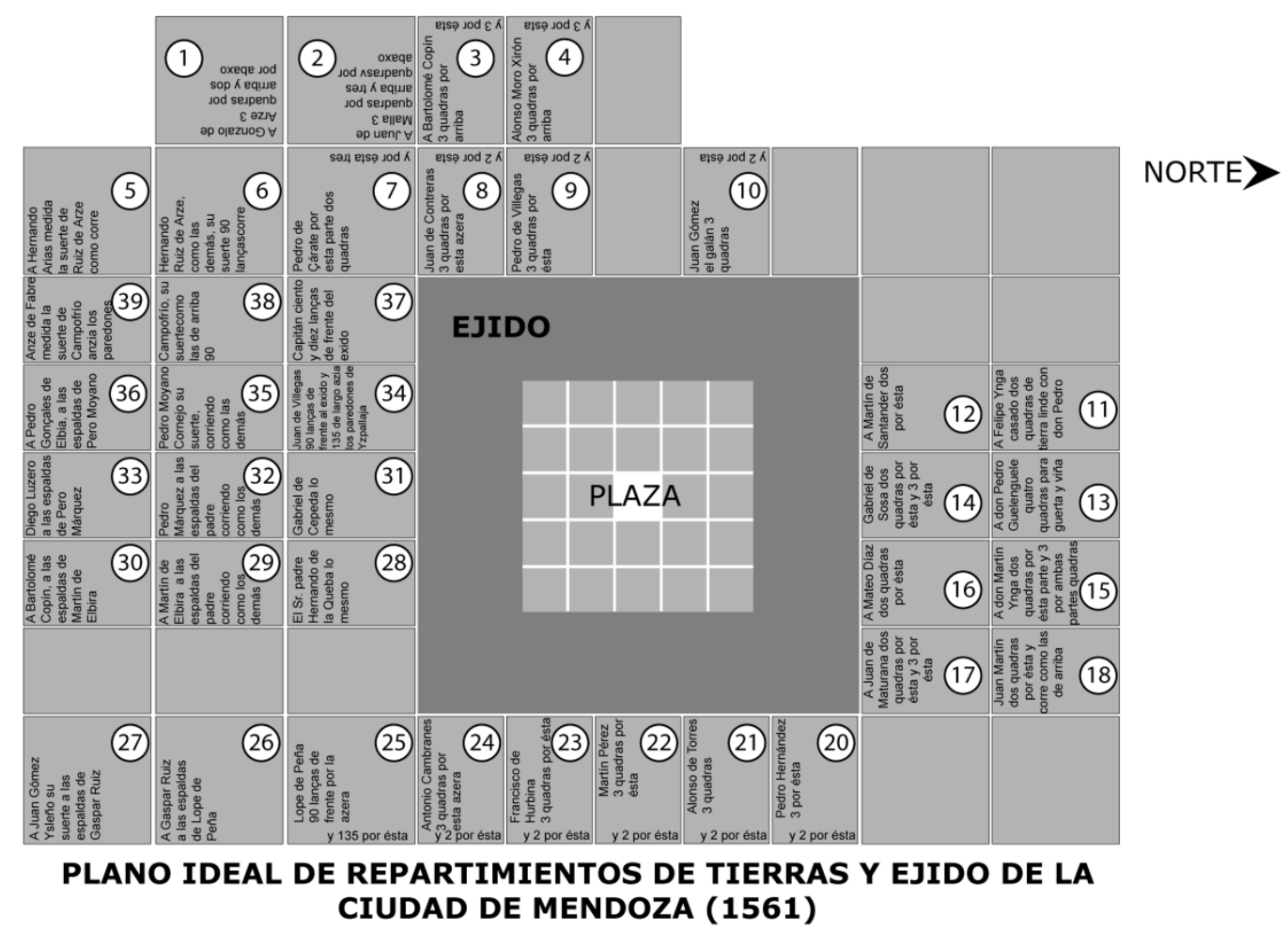

Fig. 2. Infografía territorial del "Repartimiento de tierras a los primeros pobladores de la ciudad de Mendoza" (1561) redibujado (F. Mazza).

Algunas parcelas son más grandes que otras, por ejemplo: 
e) De 90 lanzas de frente al ejido por 135 lanzas de fondo otorgadas a los vecinos Lope de Peña, Gaspar Ruíz, Juan Gómez Isleño, Juan de Villegas, Pedro Moyano, Pedro González de Elbia, Campofrío, Anze de Fabre

f) De 110 lanzas frente al ejido y 135 lazas de largo para el propio Capitán (Pedro del Castillo)

El dibujo no jerarquiza unas parcelas sobre otras, aunque sí lo hace el texto inserto en cada parcela. Tampoco podría advertirse algún tipo de privilegio respecto de algo. Porque como no está referenciado en elementos reales cualquier ubicación parece dar igual según el dibujo.

En cambio, si observamos el traspaso que hemos realizado nosotros sobre la traza probablemente real y el sistema de acequias advertiremos que los predios mejor ubicados respecto de las acequias proveedores de agua de riego y potable son los siguientes, en este orden:

La mejor parcela ubicada es la $\mathrm{N}^{\circ} 39$ que correspondía al vecino Anze de Fabre, ya que sería la primera toma de la Acequia principal del cacique Tabalqué; la segunda parcela mejor ubicada sería la del vecino (Alonso) Campofrío (de Carabajal) y la tercera la del Capitán (Pedro del Castillo) la que compensaría este tercer lugar con el hecho de estar localizada inmediatamente frente al ejido. La Acequia principal del cacique Tabalqué era la que regaba el ejido de la ciudad.

\subsection{El riego como determinante del límite del ejido}

A pesar de una primera impresión de que la empresa fundacional era algo que corría por carriles diferentes a los de la lógica situacional, sobre todo por el énfasis en los aspectos formales de la fundación y la negligencia respecto de los aspectos topográficos adónde iba a materializarse la misma. Se trataba de todo lo contrario como pretendemos demostrar en la Fig. 3.

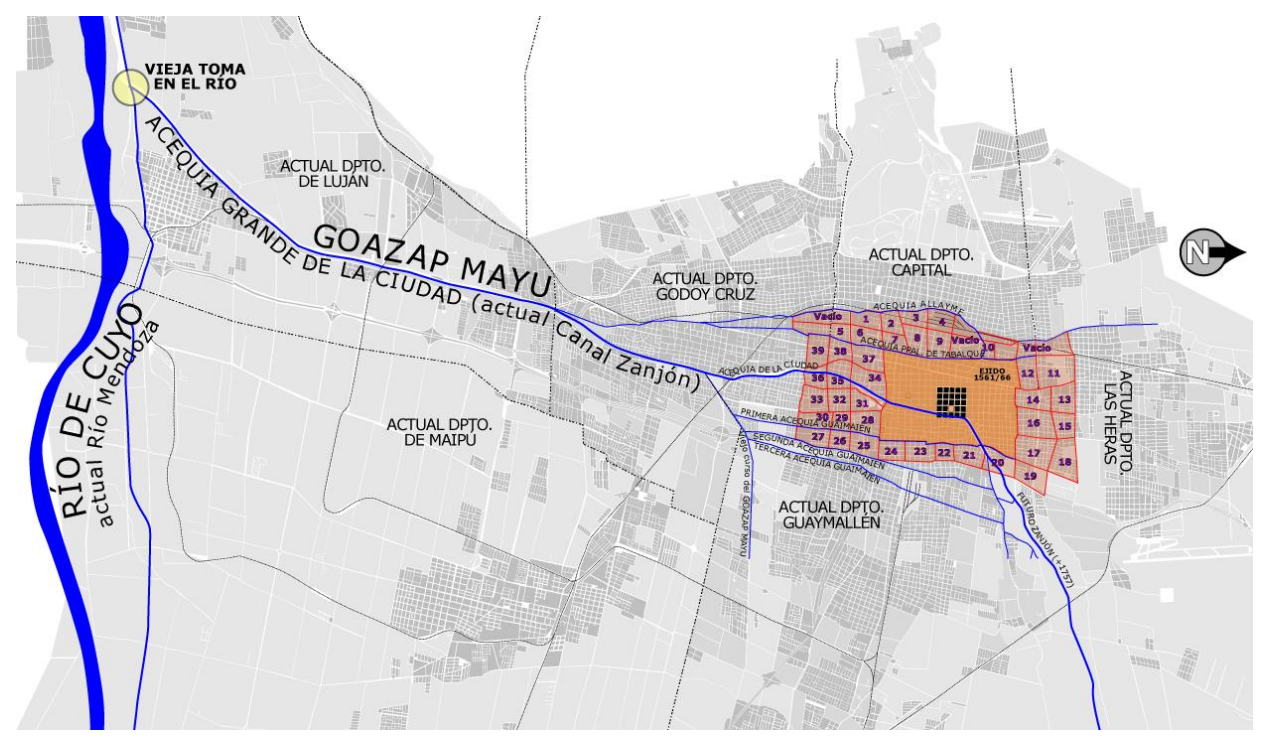

Fig. 3. Infografía que muestra la localización relativa del casco fundacional, el ejido y chacras. (dibujó F.Mazza) 
Otra cuadrícula barría con anterioridad el territorio donde se fundaría la ciudad. En efecto, esta cuadrícula virtual preexistente estaba conformada de la siguiente manera: en el sentido oeste-este barrían el territorio los zanjones aluvionales o ríos secos y desde el sur hacia el norte los barrían los canales y acequias. El entrecruce de ambos sistemas definía, de suyo, una trama parcelaria cuadrilonga. Nuestra hipótesis es que esta nueva trama, configurada por el sistema de zanjones y ríos secos por un lado y las acequias y canales por el otro, conformó, en los hechos y en el territorio, un sistema parcelario que los españoles hicieron suyo; adaptando el primer plano territorial del fundador Castillo (aquel del plano) a este otro catastro parcelario marcado en el terreno.

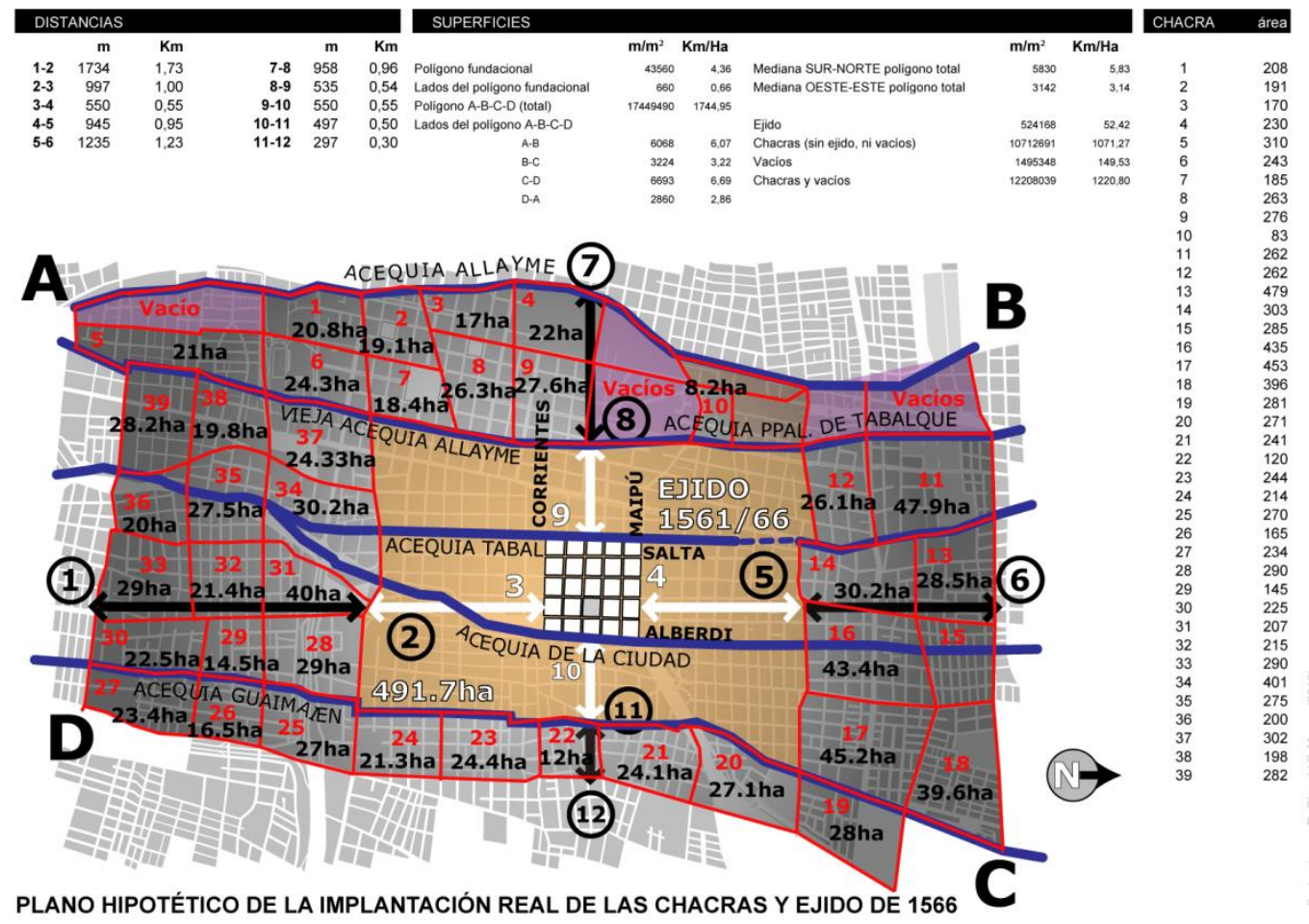

Fig. 4. Infografía Propietarios de 1561 en catastro actual.

El plano territorial de asignación de chacras alrededor de la novel ciudad, por parte del fundador, es un plano rectangular con el lado mayor indicando hacia el Norte. Detalle que marca toda una tendencia en los planos futuros de Mendoza que siempre, o casi siempre, tienen esta misma orientación. La precordillera mendocina que es próxima a la ciudad (aunque raramente se dibuja, tampoco en este plano idealizado se ubica, virtualmente, en la porción superior del plano.

A pesar que el casco urbano propuesto es un cuadrado perfecto, las tierras a asignar como chacras no equidistan del centro de la plaza fundacional. Lo que hubiera significado que este plano de ejido y chacras fuera otro plano cuadrado mayor que contuviera también al casco fundacional.

Nosotros hemos traspasado (ver fig.4) el plano idealizado del fundador (ver fig.2) sobre una traza parcelaria contemporánea y hemos dibujado, corrigiendo la ortogonalidad del plano idealizado, con la topografía histórica que conocemos de la ciudad de Mendoza. 
El resultado del traspaso del plano idealizado sobre la traza contemporánea es un nuevo dibujo (fig.4) con cinco bandas angostas y extendidas, delimitadas por sendos cursos de agua. Así vemos:

a) Banda de $6.068 \mathrm{~m}$ de largo entre los puntos A y B y $958 \mathrm{~m}$ de ancho máximo entre los puntos 7 y 8 delimitada al oeste por la acequia Allayme y por el este por la acequia que hacía las veces de colectara de las aguas de riego sobrantes, la Acequia principal del cacique Tabalqué.

b) Banda de $6.068 \mathrm{~m}$ de largo entre los puntos A y B y $535 \mathrm{~m}$ de ancho máximo entre los puntos 8 y 9 delimitada al oeste por la Acequia principal del cacique Tabalqué y por el este por la acequia que hacía las veces de colectara de las aguas de riego sobrantes, la Acequia Tabal.

c) Banda de $5.461 \mathrm{~m}$ de largo entre los puntos 1 y 6y $550 \mathrm{~m}$ de ancho máximo entre los puntos 9 y 10 delimitada al oeste por la Acequia Tabal y por el este por la acequia que hacía las veces de colectara de las aguas de riego sobrantes, la Acequia de la Ciudad.

d) Banda de $5.461 \mathrm{~m}$ de largo entre los puntos 1 y 6 y $497 \mathrm{~m}$ de ancho máximo entre los puntos 10 y 11 delimitada al oeste por la Acequia Tabal y por el este por la acequia que hacía las veces de colectara de las aguas de riego sobrantes, la Acequia de la Ciudad.

e) Banda de $6.693 \mathrm{~m}$ de largo entre los puntos 1 y 6 y $297 \mathrm{~m}$ de ancho máximo entre los puntos 11 y 12 delimitada al oeste por la Acequia Guaimaien y por el este por la acequia que hacía las veces de colectara de las aguas de riego sobrantes, innominada en los planos.

Sobre una traza parcelaria contemporánea y hemos dibujado, corrigiendo la ortogonalidad del plano idealizado con la topografía que conocemos de la ciudad histórica de Mendoza.

A los predios otorgados por el fundador los hemos numerado del 1 al 39, siguiendo el sentido de las agujas del reloj. La superficie de cada lote está inserta en cada predio (ver fig.4)

Punto 1-2. Distancia en metros: 1.734 /distancia en km: 1,7.

Punto 2-3. Distancia en metros: 997 / distancia en km: 1.

Punto 3-4. Distancia en metros: 550 / distancia en km: 0,55.

Punto 4-5. Distancia en metros: 945 / distancia en km: 0,95.

Punto 5-6. Distancia en metros: 1.235 / distancia en km: 1,23.

Punto 7-8. Distancia en metros: 958 / distancia en km: 0,96.

Punto 8-9. Distancia en metros: 535 / distancia en km: 0,54.

Punto 9-10. Distancia en metros:550/distancia en km: 0,55.

Punto 10-11. Distancia en metros: 497 / distancia en km: 0,50.

Punto 11-12. Distancia en metros: 297 / distancia en km: 0,30.

Superficie polígono fundacional: $43.560 \mathrm{~m}^{2} /$ 4,36 ha.

Lados del polígono fundacional: $660 \mathrm{~m} / 0,66 \mathrm{~km}$.

Superficie del polígono A-B-C-D repartimientos: $17.449 .490 \mathrm{~m}^{2} / 1.744,95$ ha.

Lados del polígono A-B: $6.068 \mathrm{~m} / 6,07 \mathrm{~km}$.

Lados del polígono B-C: $3.224 \mathrm{~m} / 3,22 \mathrm{~km}$.

Lados del polígono C-D: $6.693 \mathrm{~m} / 6,69 \mathrm{~km}$.

Lados del polígono D-A: $2.860 \mathrm{~m} / 2,86 \mathrm{~km}$.

Mediana SUR-NORTE polígono total: $5.850 \mathrm{~m} / 5,83 \mathrm{~km}$.

Mediana OESTE-ESTE polígono total: $3.142 \mathrm{~m} / 3,14 \mathrm{~km}$.

Superficie EJIDO fundacional: $524.168 \mathrm{~m}^{2} / 52,42$ ha.

Superficie CHACRAS (sin Ejido ni vacíos): $10.712 .691 \mathrm{~m}^{2} / 1071,27$ ha.

Superficie VACÍOS: $1.495 .348 \mathrm{~m}^{2} / 149,53$ ha.

Superficie CHACRAS y VACÍOS: $12.208 .039 \mathrm{~m}^{2} /$ 1.220,80 ha. 
Este plano territorial establece diferentes medidas longitudinales desde el casco urbano hacia el borde del ejido, ya se trate del límite oeste (958 m), del límite sur (997 m), del límite este $(497 \mathrm{~m})$ y del límite norte $(945 \mathrm{~m})$. Estas diferencias se explican porque, aunque el plano no lo explicite ni lo insinúe de ninguna manera, lo que se está teniendo presente para confeccionar este plano es la información ausente: son dos acequias indígenas preexistente, la más hacia el oeste era la Acequia Allayme y la más hacia el este era la Acequia Guaimaien entre las cuales se está ubicando la ciudad más su ejido más sus chacras.

Esto no podría ser de otra manera ya que en una zona semidesértica como el entonces $V$ alle de Huantata no había otro posibilidad de establecimiento de la vida humana y productiva si no fuera a través de acequias o canales que trajeran el agua desde la toma en el río a $20 \mathrm{~km}$, distancia que media entra la ciudad fundada y el entonces Río de Cuyo, actual Río Mendoza.

Todo este trazado hídrico que posibilitaba tener un sistema de irrigación que naciendo del Rio proveyera de agua a la planicie había sido obra de los aborígenes, fueran éstos los buarpes o los incas, información que carecemos porque ambas culturas, tanto la Huarpe como la Inca, fueron culturas ágrafas. Tampoco nadie parece haber preguntado nunca a los indígenas quien trazó el sistema de riego prexistente a la llegada de los españoles. La única Acta que lo podría haber dicho, la llamada Acta de los Caciques Comarcanos de 1574 (Ponte, 2008) no aborda este tópico importante hoy para nosotros pero deleznable para los conquistadores.

La distancia entre estas dos acequias Huarpes era variable ya que se acercan o se alejaban según la topografía del terrenos con pendiente suroeste-noroeste. Así, en el borde sur del polígono esta distancia es de $2.860 \mathrm{~m}$ y en el borde norte, es levemente superior de 3.224 $\mathrm{m}$. Mientras que en la porción media ronda los $2.837 \mathrm{~m}$.

La lógica de la distribución de los solares y chacras era la siguiente:

a) la primera banda de chacras de oeste a este entre los puntos $\mathrm{A}$ y $\mathrm{B}(6.068 \mathrm{~m})$ debían poder proveerse de agua de riego y potable desde el suroeste con dirección noreste con tomas en que la acequia proveedora que era la Acequia Allayme.

b) la segunda banda de chacras de oeste a este entre los puntos A y B (6.068 m) debían poder proveerse de agua de riego y potable desde el suroeste con dirección noreste con tomas en que la acequia proveedora que era la Acequia Principal del cacique Tabalqué.

c) la tercera banda de chacras de oeste a este, hacia abajo de los puntos A y B $(6.068 \mathrm{~m})$ debían poder proveerse de agua de riego y potable desde el suroeste con dirección noreste con tomas en que la acequia proveedora que era la Acequia Tabal proveniente de la Acequia Grande de la Ciudad.

f) la cuarta banda de chacras de oeste a este, a la altura de los puntos 1 y $6(5.461 \mathrm{~m})$ debían poder proveerse de agua de riego y potable desde el suroeste con dirección noreste con tomas en que la acequia proveedora de la Acequia Grande de la Ciudad en su porción sur y la Acequia Alta de Tantaiquén luego llamada Acequia de la cindad. 
d) la quinta banda de chacras de oeste a este, a la altura de los puntos D y C $(6.693 \mathrm{~m})$ debían poder proveerse de agua de riego y potable desde el suroeste con dirección noreste con tomas en que la acequia proveedora de la Acequia Guaimaien en todo su trayecto, de sur a norte.

El ejido de la ciudad de 52,42 ha estaba irrigado desde el oeste por la Acequia Principal del cacique Tabalqué más la Acequia Tabal y la Acequia Alta de Tantaiquén luego llamada Acequia de la cindad.

\section{El ejido y las chacras en el plano de la ciudad en 1754}

Luego de 1561, no aparecen nuevos planos de la ciudad de Mendoza o de sus alrededores sino hasta 1750 en que en el Archivo Nacional de Chile aparecen algunos planos de mensura de particulares en tierras de Mendoza con los cuales podamos establecer diferencias y semejanzas. Este documento es el primer plano real sobre la Ciudad de Mendoza que creemos que existe. Es decir, el más próximo en el tiempo es el plano de asignación de solares y chacras por parte del fundador de la ciudad, el capitán español Pedro del Castillo [1561].

Respecto de la ciudad, la novedad fue la aparición del denominado por nosotros plano Mayorga-Jurado de tierras de María Miranda y otros, 1754. Se trata de un plano mandado confeccionar por el maestre de campo Ángelo Francisco Mayorga y Fernando Jurado inserto en un expediente de un pleito que ellos le inician a Doña María Miranda por el cierre de una calle que, para los denunciantes sería una calle Real y para la denunciada sería una calle privada.

En la Mapoteca del Archivo Nacional de Chile está catalogado como: Real Audiencia de Chile, plano № 1, volumen 190, fjs 30. Es importante reportarlo porque muestra, por primera y única vez en un documento catastral de los siglos XVIII, los sitios o parcelas urbanas y semi-rurales ubicados en una franja horizontal que va: desde Cnel. Díaz hasta el Zanjón Maure y desde la Acequia Principal del cacique Tabalque hasta la Acequia de la Cindady otros sitios alrededor de la actual calle Salta, obviamente, no conocida con este nombre, sino que en plano está identificada como "calle de sur a norte".

En los actuales distritos de San José y Dorrego se indica: "Tierras... de varios vecinos... que están pobladas... de la Acequia de la Ciudad a la parte del naciente”. De lo que infiere que la acequia inmediatamente a la izquierda de la referida leyenda es la Acequia de la Ciudad, como habíamos supuesto.

Respecto de dicho plano fundacional de repartimiento de solares y establecimiento del ejido [ver reproducción en este mismo trabajo] el cambio más trascendente es la existencia de una lógica de asentamiento que se advierte en el este plano, donde todo se organiza alrededor de los cursos de agua, conocidos como acequias. En este plano hay indicadas y dibujadas tres acequias, dos paralelas: el nuevo curso de la acequia Allayme o Acequia Principal del cacique Tabalque y la acequia que acompaña a la calle de sur a norte [Salta] para nosotros $2^{\mathrm{a}}$ acequia de Tabalque y una divergente, la denominada Acequia de la Ciudad.

Otro valor adicional de este plano de 1754 es el hecho que constituye un documento anterior a la aparición del Zanjón [actual Canal Zanjón] en 1757. Por lo tanto, puede darnos una idea del funcionamiento del sistema hídrico, en torno al casco urbano histórico, 
antes del colapso que significó la formidable zanja que se formó en la parte posterior de la manzana del Cabildo.

También este plano de María Miranda es previo al cambio de curso del Desagüe viejo por el Desagüe nuevo, ya que también es anterior al plano territorial de 1761 que proponía dicha modificación como una forma de atemperar el efecto del ingreso de exceso de aguas desde el río y desaguar las aguas sobrantes de la Acequia Grande de la Ciudad [actual Canal Zanjón] e impedir que éstas entraran a la Ciudad de Mendoza, produciendo estragos, situación de peligro que se había originado con la aparición del Zanjón en la porción oeste del casco urbano dieciochesco.

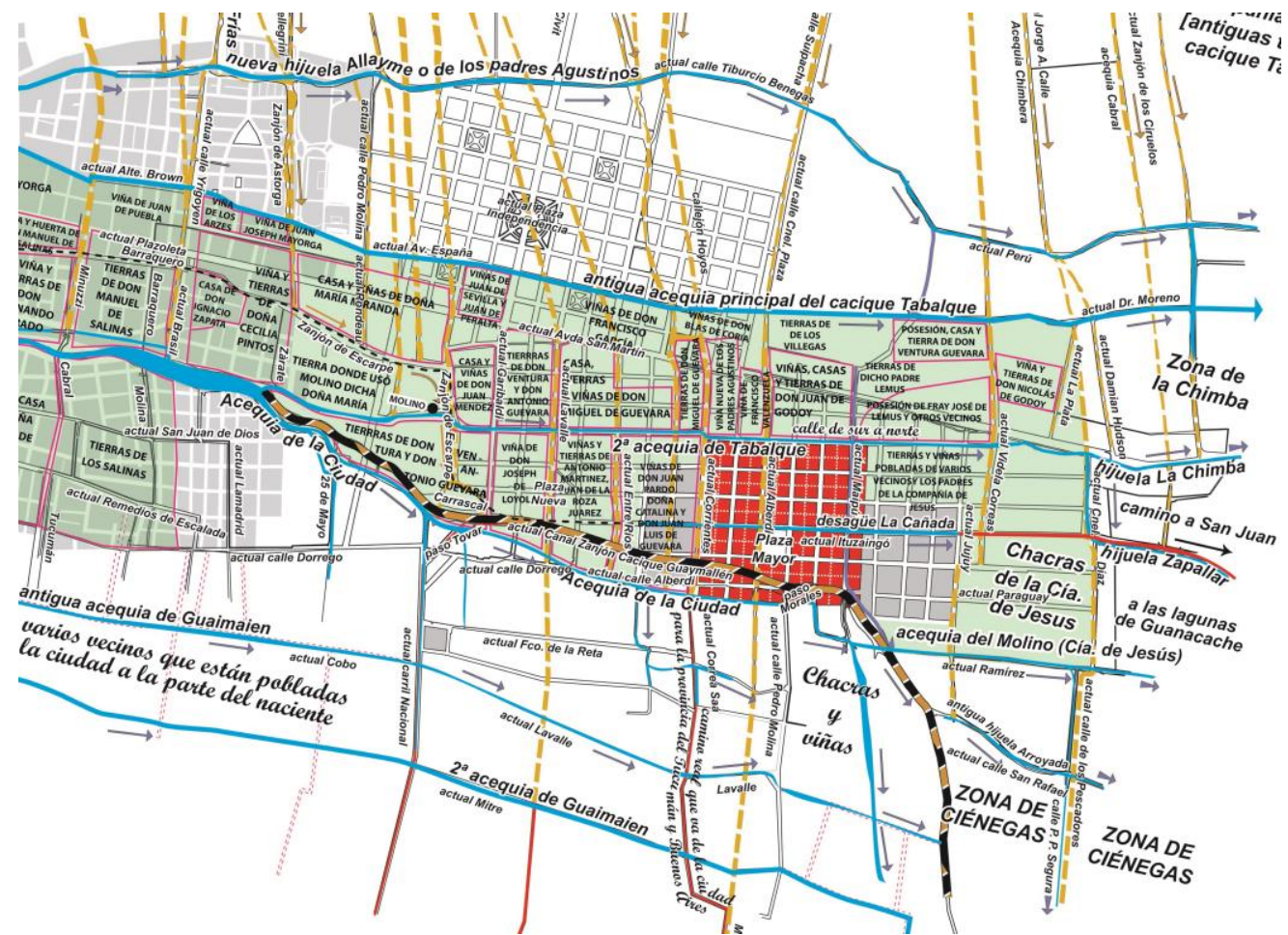

Fig. 5. El ejido de 1561 visto en el plano de 1754 traspasado al catastro actual

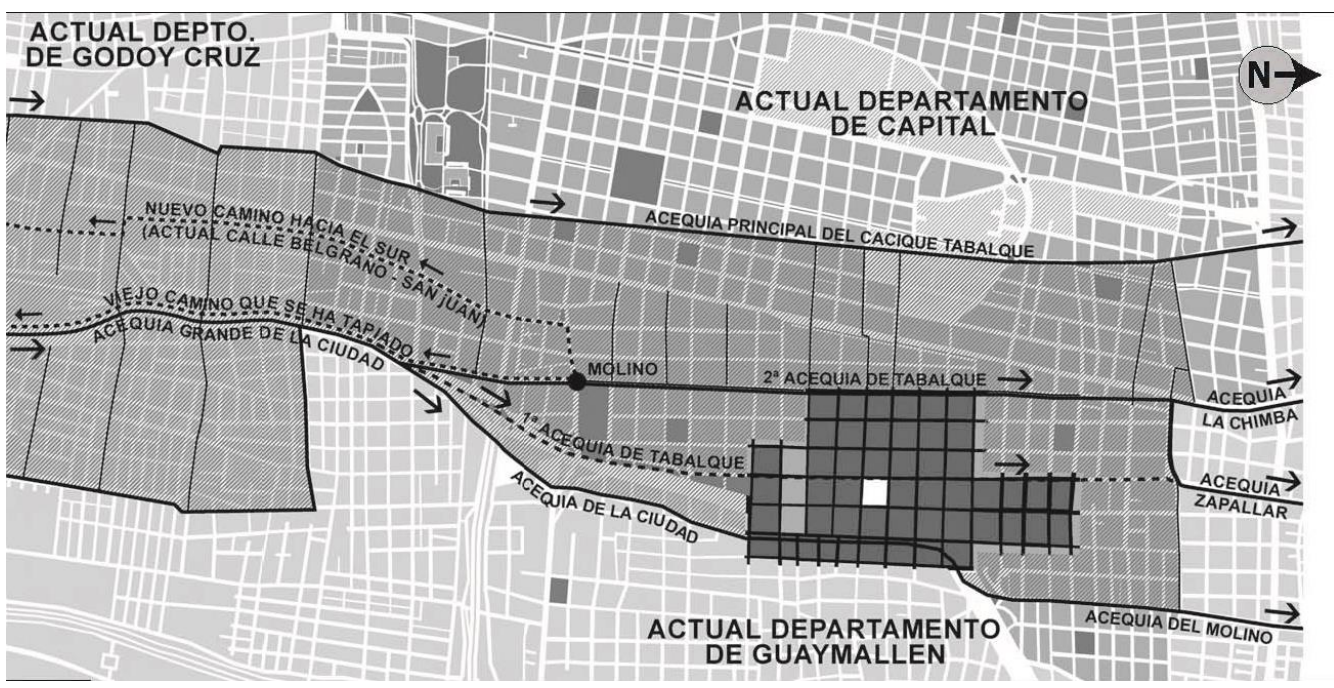

Fig. 6. La ciudad de Mendoza en 1754 con el ex ejido y chacras de 1561 y sus acequias históricas 


\section{Comparación entre los planos territoriales de 1561 y de 1754}

Una primera observación que resalta es que el límite oeste de la ocupación del territorio en 1754 -Acequia Principal del cacique Tabalqué- es menor que el propuesto en 1561, es decir, las chacras regadas por la Acequia Allayme.

Esta diferencia puede deberse a que el lugar donde se fundó la ciudad era un territorio ya ocupado por los aborígenes, es decir, no eran "tierras vacas" y las acequias disponibles respondían a la lógica previa de ocupación y explotación del territorio por parte de los naturales.

En efecto, la indígena Acequia Allayme que había sido prevista como límite oeste del repartimiento del fundador en 1561, era una acequia que llevaba agua a las tierras del cacique Tabalqué, dueño y señor de las tierras en la porción norte de la ciudad fundada por los españoles. De ser así, la Acequia Allayme circunvalaba la ciudad y su ejido. Por ello, no regarían durante todo el trayecto de su trazado, o por el hecho de ser tierras de los aborígenes se las incluía pero no se las disponía.

A ello puede deberse que, mientras en 1561 se establecían en esta zona de arrabal la cantidad de predios y sus propietarios, en el de 1754 no hay identificados propietarios lo que puede significar que: o el espacio previsto en 1561 fue mayor del necesario de ocupar o que todos los propietarios asignados a este sector se corrieron hacia el este ocupando el espacio previsto para el ejido, o sea, para estar más próximos al casco urbano.

Si bien el nombre de acequia puede suponer una jerarquía menor a la de canal, ello no siempre es así. En efectos, existen algunos canales históricos que son llamados Acequias por motivos históricos. Tales serían el caso de la: Acequia Allayme, Acequia Grande de la Ciudad, Acequia Alta de Tantaiquén, Acequia de la ciudad, Acequia Principal del cacique Tabalqué.

\section{Los tres cursos de la histórica Guaimaien Sequia}

En el territorio donde se asienta el actual Área Metropolitana de Mendoza el sistema de irrigación es posible por el suave declive que tiene el glacis donde se asienta, que tiene una pendiente suroeste-noreste de un valor que oscila entre el 2,2\% y 1,4\%. Salvo el cauce más importante, el actualmente conocido como Canal Zanjón, que discurre sobre una falla geológica del terreno con sentido sur-norte, el resto del sistema de canales y acequias aprovechan también fallas geológicas menores para fijar al territorio sus trazados. Tales serían los canales sur-norte, algunos de origen indígena y otros del período colonial.

La perdurabilidad de los recorridos de los canales e inclusive de sus nombres es muy importante ya que la vinculación de la tierra al derecho de riego es una característica del uso del agua en Mendoza que incluso tiene respaldo constitucional.

Un caso interesante sobre la movilidad del curso de las acequias del cual tenemos registro es el caso de la Guaimaien Sequia. Esta acequi histórica es una de las cuatro primeras acequias que se blanquean en el Acta Capitular de 1566 a los cinco años de fundada la ciudad (1561). Era el curso de agua más hacia el este de los cuatro enunciados.

Esta acequia nace de un brazo de la Acequia Grande de la Ciudad [actual Canal Zanjón] llama $\neg$ do tradicionalmente "el Desagüe", otrora tan importante que algunos autores como 
Draghi Lucero, afirman que fue el antiguo curso del Zanjón (Draghi, 1985). Actualmente se lo conoce como canal Confín Desagüe-hijuela Mathus Hoyos, con toma un poco más hacia el sur de la toma del Tajamar, y su primera dirección es al sesgo, a $45^{\circ}$ para girar abruptamente hacia el este.

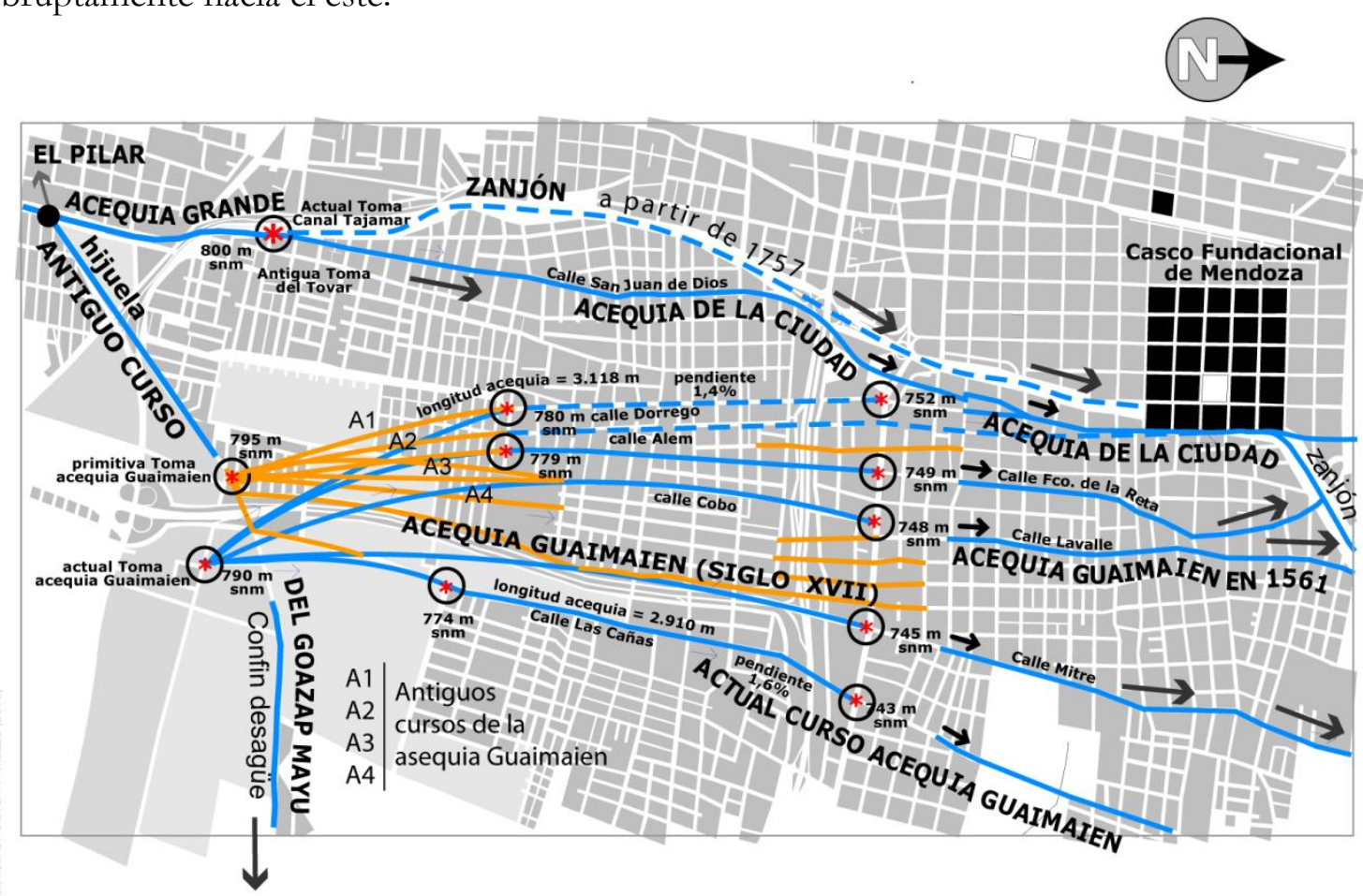

Evolución de los cursos históricos de la acequia GUAIMAIEN

Fig. 7 Variaciones Acequia Guaimaien siglo XVI-XVIII en catastro actual

Es precisamente en este sitio, donde nace la Guaimaien-cequia-como dice el próximo plano de 1802. Su curso es sur-norte, igual que las otras tres principales que nacían del Desagüe, y que volvían a unirse al Zanjón en la zona llamada "Bermejo".

La actual zona de Dorrego era aquella donde vivía el cacique Goaymaye, de allí se explica que la acequia que pasaba por sus tierras se la asociara con el nombre de acequia de Guaymallén, pero lo más probable es que deba su etimología al hecho de ir a morir a las ciénagas. Sería ésta la primera y más importante de las tomas del Desagüe. En tiempo que no nos es dable verificar [antes de 1750], su toma se corrió más hacia el este, a la altura de calle Mitre para morir en la capilla de Nieva. Ya que un plano existente en el Archivo Nacional de Chile de 1758 habla de la entonces acequia de Guaimaien como la "que hoy llaman de Guaimaien” lo que induce a pensar que "antes", o no existía o se llamaba de otra manera [¿tal vez acequia de Sotomayor?].

Según creemos, han existido tres acequias Guaimaien, todas ellas con el mismo lugar de toma en el Desagüe. Lo que ha ido variando entre ellas ha sido la dirección del ángulo con que discurrían hacia el norte. Así la primera acequia Guaimaien [siglo XVI] sería la luego conocida como "hijuela del Infiernillo", que corría por la calle Cobo de Dorrego y que penetraba profundamente en el distrito de San José, por la actual calle Lavalle, para desaguar en la Capilla de Nieva o en el propio Canal Zanjón. Esta $1^{\text {a }}$ acequia de Guaimaien habría sido el límite este del ejido de la ciudad establecido en 1566 y se comprende el por qué, ya que a partir de ella comenzaban las chacras que regaba esta acequia. 
La $2^{\mathrm{a}}$ acequia Guaimaien [siglo XVIII y XIX] se encauzaba por calle Primitivo de la Reta hasta llegar al Carril Nacional Ba de los Andes donde tomaba por la calle Mitre de Pedro Molina para ir a morir a la Capilla del Capitán Juan Nieva en la zona de la Lagunita. La $3^{\text {a }}$ acequia Guaimaien [siglo $\mathrm{XX}$ ] se encauza por calle Las Cañas hasta llegar al Carril Nacional Ba de los Andes desde donde toma por la calle Allayme de Pedro Molina para ir a morir a la ex Capilla del Capitán Juan Nieva en la zona de la Lagunita. La actual acequia de Guaymallén, aunque también toma del Desagüe unos $400 \mathrm{~m}$. más hacia el este, se va abriendo al sesgo hacia el nordeste hasta llegar a unos 1.200 metros más hacia el este que el antiguo curso de la Guaimaien-cequia, en la prolongación de la antigua plaza fundacional [actual Pedro del Castillo].

Existe un expediente en el Archivo Histórico de Mendoza (en adelante A.H.Mza) de Pedro Nolasco Rivas contra Francisco Romero por impedirle el uso de la acequia regadora en la zona actualmente conocida como San José del Dpto. de Guaymallén. En estas actuaciones, Pedro Nolasco (viudo de María Josepha Guevara) se queja porque Romero no lo deja regar por la misma acequia que lo han hecho siempre. Pide vista de ojos y ésta dictamina que no hay otro lugar por donde pueda pasar la acequia. Ésta pasa por las tierras del Maestre de Campo Sebastián de Sotomayor y de Doña Petrona Jofré. El cabildo dictamina que Ribas, Romero y los demás interesados se comprometan abrir y mantener la acequia (siguen sin nombrarla).

Más adelante el documento incluye una nota firmada por algunos vecinos al Cabildo donde se quejan de la medida. Se autodenominan "los interesados en acequia de Guaimallén). El documento continúa afirmando que dicha acequia de Guaimaien trae poca agua y que "mueve dos molinos" (Uno de ellos debe ser el Molina y el otro lo ignoramos) ${ }^{9}$.

\section{Conclusión}

En América, en general, y en el territorio sudamericano que conformó el Imperio Incaico, en particular, existió una cultura hidráulica, consistente en refinadas técnicas de represas, canales y acequias. Estos sistemas hidráulicos, preexistentes en la actual Mendoza a la llegada de los conquistadores, condicionaron la implantación del asentamiento urbano español. Pero, los recién llegados, se cuidaron mucho de dar cuenta de ello en sus actas fundacionales, o dar precisiones gráficas acerca de esa cultura hidráulica de alta eficiencia, por varios motivos. Entre ellos el justificar su dominación, ya que los aborígenes locales debían aparecer como una cultura más atrasada tecnológicamente y no lo eran para nada.

En el período colonial español existieron numerosos litigios por problemas del uso del agua (potable y de riego) que tenían a las acequias como protagonistas. Estos conflictos entre vecinos, entre ellos e instituciones religiosas, entre vecinos y molineros, etc., fueron, muchas veces, acompañados de planos explicativos que intentaban argumentar, gráficamente, dichas disputas.

En dichos planos históricos, al no saberse traspasar espacialmente dichos alegatos o no poderse técnicamente traspasar dichos planos sobre la traza contemporánea, no resultaba fácil identificar espacialmente donde ocurría lo que se relataba en el alegato. Por lo tanto, quedaba como una información aislada que no tenía mucha vinculación visible con el presente.

9 A.H.Mza. Carpeta № 36. Obras de riego. Colonial. Documento 13. 22/10/1774. 
Por ello, nuestro objetivo ha sido mostrar las posibilidades que se abren en la investigación histórica, mediante la utilización de la cartografía hidráulica histórica re visitada con la tecnología digital del presente. Procesarlos mediante programas gráficos (que no es lo mismo que escanear ni tampoco hacer geo-referenciación). Para, finalmente, contextualizar estos planos hidráulicos re-trabajados en el proceso histórico y político en el cual se insertaban. El resultado o producto obtenido de este proceso de digitalización y graficación ha sido la incorporación al corpus cartográfico tradicional mendocino de nuevos planos históricos.

Por otro lado, existen en el territorio mendocino cuestiones topográficas, tales como ríos secos, cañadones, barrancos, cambios abruptos de pendientes, cursos de agua, ríos, arroyos, etc. que, aunque vienen desde tiempos inmemoriales, no fueron registrados en los primeros planos coloniales y sí, en cambio, en los del siglo XIX. Con esta información disponible, digitalizada y traspasada sobre la traza contemporánea pudimos re-visitar los planos coloniales incorporándole todo la información topográfica faltante en oportunidad de su levantamiento. Con ello podemos recrear una cartografía didáctica de mucha utilidad.

Una primera conclusión que surge es que, lejos de lo que suele pensarse, el "damero español" no tuvo un mecánico traspaso en el territorio de las ciudades americanas fundadas durante el proceso colonizador español. Por el contrario, este "damero ideal" traído en la mente de los conquistadores y puesto de manifiesto en los primeros planos fundacionales por ellos levantados, debió adaptarse al "topos" local, y a las necesidades de provisión de agua potable, de riego de chacras y huertas o de desagüe urbano.

Finalmente, se hace necesario y evidente tener como premisa la necesidad de "incorporar espacio a la historia e historia al territorio". Solo espacializando la historia, o el relato histórico, e historizando el espacio social y cultural podremos comprender y modificar la tensión que anida entre la historia y el territorio.

\section{Referencias}

Cortellezzi, M., Schilan, R., \& Prieto, E. (2013). Excursión por la Ciudad de Mendoza. Departamento de Geografía, Facultad de Filosofía y Letras, U.N.Cuyo , Fecha: 23 de Mayo de 2013.

Maza, J. I. (1990). Toponimia, Tradiciones y Leyendas Mendocinas. Mendoza: Fundación Banco de Boston.

Page, C. A. (2004). Los ejidos como espacio comunal de la ciudad. Revista de indias, vol. Ixiv (232), 635-650.

Ponte, J. R. (2006). De los caciques del agua a la Mendoza de las acequias. Cinco siglos de historia de acequias, zanjones y molinos. Mendoza, Mendoza, Argentina: Ediciones "Ciudad y Territorio" INCIHUSA-CONICET.

Ponte, J. R. (2008). Mendoza, aquella ciudad de barro. Ilustrado. Historia de una ciudad andina, desde el siglo XVI hasta nuestros días. Buenos Aires: CONICET de Argentina, Imprenta Unión.

Wyrobisz, A. (1980). La ordenanza de Felipe II del año 1573 y la construcción de ciudades coloniales españolas en la América. Estudios Latinoamericanos 7. 